\title{
Extrahepatic portosystemic venous shunt presenting as galactosaemia
}

\author{
Chisato Akita • Tsuneyuki Nakamura
}

Received: 12 June 2009/Revised: 20 August 2009 /Accepted: 21 August 2009 / Published online: 19 January 2010

(C) Springer-Verlag 2010

A newborn screening program identified a 23-day-old asymptomatic girl with elevated serum galactose $(>18.3 \mathrm{mg} / \mathrm{dl})$ after breast feeding. The enzymes that metabolise galactose showed normal activity, thereby excluding hereditary galactosaemias. Three-dimensional CT venography (Fig. 1) showed direct portocaval communication between the inferior mesenteric vein and the left internal iliac vein. Inferior mesenteric venous portography via the shunt confirmed that the flow was hepatofugal through the communication (Fig. 2). Intrahepatic

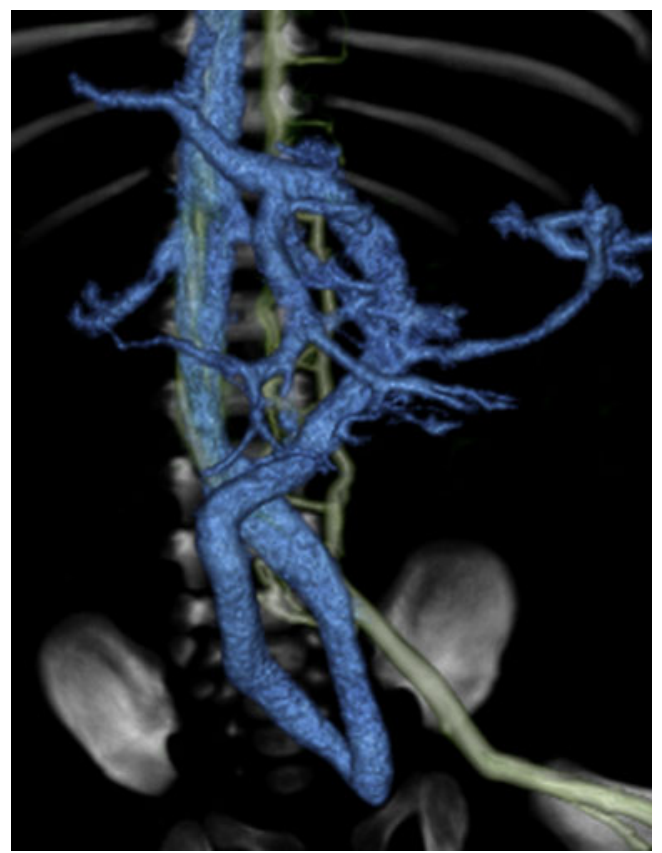

Fig. 1 3-D CT venography

C. Akita $\cdot$ T. Nakamura $(\bowtie)$

Department of Paediatrics, Kanazawa Medical University,

1-1 Daigaku, Uchinada-machi, Kahoku-gun,

Ishikawa 920-0293, Japan

e-mail: p-tune@kanazawa-med.ac.jp

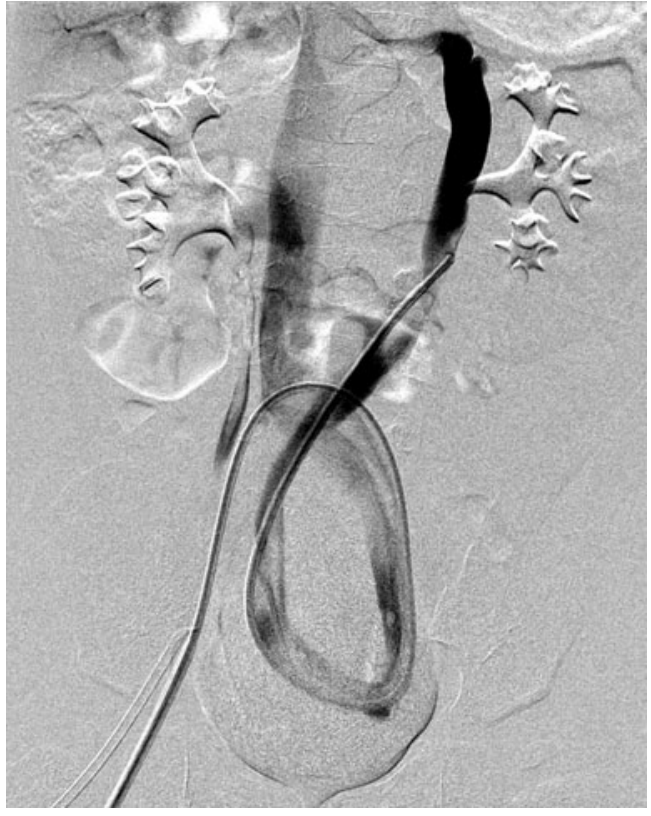

Fig. 2 Inferior mesenteric portography

portal venous supply was preserved. The girl was treated with catheter embolisation.

Congenital extrahepatic portosystemic (PS) venous shunt is a rare form of PS shunt that can cause hypergalactosaemia in infants $[1,2]$. These malformations may lead to severe complications, such as heart failure, pulmonary hypertension, encephalopathy and hepatic tumours, and necessitate life-long follow-up if closure is not performed [1,2].

\section{References}

1. Murray CP, Yoo SJ, Babyn PS (2003) Congenital extrahepatic portosystemic shunts. Pediatr Radiol 33:614-620

2. Ono H, Mawatari H, Mizoguchi N et al (1998) Clinical features and outcome of eight infants with intrahepatic porto-venous shunts detected in neonatal screening for galactosaemia. Acta Paediatr 87:631-634 